\title{
TITLE:
}

\section{$<$ Note> Exploratory-threat behaviors in wild chimpanzees encountering a porcupine}

$\operatorname{AUTHOR}(S)$ :

Matsusaka, Takahisa

\section{CITATION:}

Matsusaka, Takahisa. <Note> Exploratory-threat behaviors in wild chimpanzees encountering a porcupine. Pan Africa News 2007, 14(2): 29-31

ISSUE DATE:

2007-12

URL:

http://hdl.handle.net/2433/143480

RIGHT:

Copyright (C) Pan Africa News. 
<NOTE>

Exploratory-threat behaviors in wild chimpanzees encountering a porcupine

Takahisa Matsusaka

Japan Monkey Centre, Japan 


\section{INTRODUCTION}

To my knowledge, there has been no report on direct interactions between wild chimpanzees and porcupines. This paper reports the observation of an encounter between wild chimpanzees and a crested porcupine (Hystrix cristata) in the daytime at Mahale Mountains National Park, Tanzania.

\section{OBSERVATIONS}

At noon on November 22, 2000, while following a group of travelling chimpanzees, I found some chimpanzees resting, with a porcupine near them (12:04). This party of chimpanzees consisted of 1 adult female (FT), 3 adolescent males (PM, PR, CD), 1 juvenile female (IV), and 2 infant females (FV, IM). The porcupine kept still on the ground and took a defensive posture, with its head under a dense thicket of vines and the quills on its back extending into the open space (Fig. 1).

The chimpanzees stayed about $2-7 \mathrm{~m}$ from the porcupine. At 12:06, a 9-year-old male (PR) approached the porcupine from behind and hit the ground $1 \mathrm{~m}$ behind it with a small stick ( $1 \mathrm{~cm}$ diameter by $20 \mathrm{~cm}$ long). At the same time, an 8-year-old male (CD) shook the thicket $3 \mathrm{~m}$ above the porcupine. Then, PR sat $1.5 \mathrm{~m}$ behind the porcupine, broke another nearby branch $(3 \mathrm{~cm}$ diameter by $70 \mathrm{~cm}$ long), extended it toward the porcupine cautiously, and then strongly hit the ground with it right behind the porcupine 6 times (12:07). The branch never touched the body or quills of the porcupine, but the porcupine slightly projected its quills outward and spread them open. PR lay about $1 \mathrm{~m}$ behind the porcupine with his belly on the ground and stared at it for a while (Fig. 2), and finally he

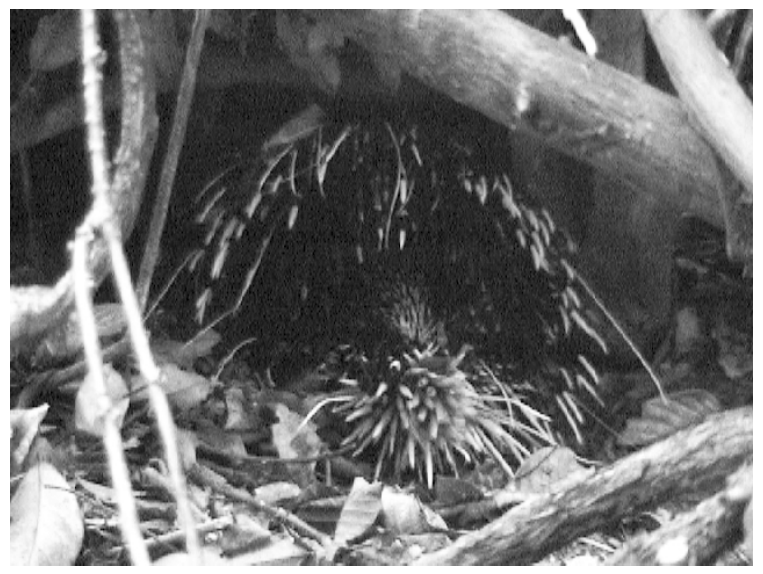

Fig. 1 A porcupine in a defensive posture.

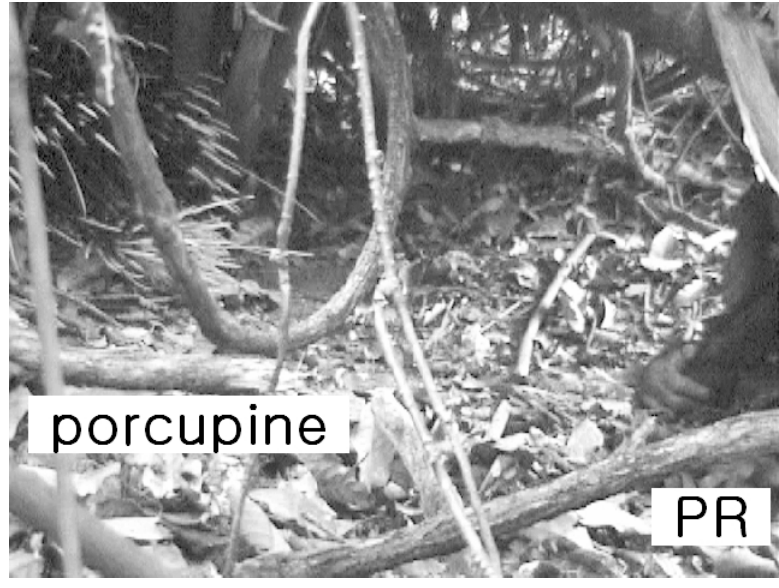

Fig. 2 PR (right) staring at the porcupine from behind.

left the site (12:08). Then a 2-year-old female (IM) shook the thicket $2.5 \mathrm{~m}$ above the porcupine as CD did, and the quills were again slightly extended. At 12:09, an adult female (FT), who sat $2 \mathrm{~m}$ from the side of the porcupine, pulled and shook a vine stretched from the thicket around the porcupine. After that, the porcupine turned its head toward FT, and FT barked "Wo! Wo!" and again shook the vine intensely. This made the porcupine return to its original posture, with the head under the thicket, and FT calmed down. A 1-year-old female infant of FT (FV) also watched the porcupine from a distance of about $2 \mathrm{~m}$. At $12: 13$, a chorus of pant hooting occurred around the site, and the porcupine again made its quills up and open. At $12: 14$, the chimpanzees started to leave the site. A 12-year-old male (PM) was once about to pass behind the porcupine but then changed his course, passing in front of the porcupine.

\section{DISCUSSION}

Four out of the seven chimpanzees at the site showed threat-like displays near the porcupine. Aggressive behaviors of chimpanzees toward another species have been observed during hunting ${ }^{1}$, counterattack against a predator $^{2,3}$, and cross-species play or playful teasing ${ }^{2,4}$ The threat-like displays observed in this study were not considered hunting attempts, since there is no record of chimpanzees hunting porcupines ${ }^{1}$ and the displays were not as vigorous or the chimpanzees as excited as during genuine hunting. These displays were not a counterattack against a predator because the porcupine is herbivorous and in this case assumed a defensive posture throughout the encounter. These displays were more likely playful 
teasing; however, the chimpanzees seemed to engage in this behavior not simply for enjoyment. Rather, the chimpanzees seemed a little nervous and careful about the potential danger: They usually remained several meters from the porcupine, they used sticks or vines instead of touching or biting directly, and they did not show play face nor emit play panting (cf. 4, 5). Despite their caution, the chimpanzees intentionally took actions toward the porcupine, which kept still. These ambivalent behavior patterns suggest that their threat-like displays should be more appropriately regarded as "exploratory-threat behaviors," by which chimpanzees tried to elicit some reactions from the porcupine to learn whether it was dangerous or how it might be dangerous.

Since the porcupine is a nocturnal animal, it is probable that chimpanzees rarely encounter this animal and know little about it. This may be one of the reasons why chimpanzees engaged in exploratory behaviors toward the porcupine even though they were careful about the potential danger. The fact that not only immature chimpanzees but also the adult engaged in exploratory behaviors further suggests that encounters with porcupines are very rare for the $\mathrm{M}$ group chimpanzees of Mahale.

Acknowledgments. The field work on which this paper is based was financially supported by the MEXT Scientific Research Fund A1 (\#12375003 to Toshisada Nishida). The analysis of the video footage was financially supported by the Global Environment Research Fund of the Ministry of Environment (F-061 to Toshisada Nishida).

\section{REFERENCES}

1. Uehara S 1997. Predation on mammals by the chimpanzee (Pan troglodytes). Primates 38: 193-214.

2. Goodall J 1986. The Chimpanzees of Gombe: Patterns of Behavior. Harvard University Press, Cambridge.

3. Hiraiwa-Hasegawa M, Byrne RW, Takasaki H, Byrne JME 1986. Aggression toward large carnivores by wild chimpanzees of Mahale Mountains National Park, Tanzania. Folia primatol 47: 8-13.

4. Zamma K 2002. A chimpanzee trifling with a squirrel: pleasure derived from teasing? Pan Afr News 9(1):9-11.

5. Matsusaka T 2004. When does play panting occur during social play in wild chimpanzees? Primates 45: 221-229. 